\title{
¿Qué sucederá durante la jornada electoral del primero de julio en el contexto de las redes sociales?
}

\author{
Equipo de trabajo \\ del Observatorio Electoral 2.012*
}

\section{Sumario:}

I. La primera vuelta de la elección presidencial francesa del 22 de abril de 2012

II. El caso de LaTribune de Genève en 1997

III. La reincidencia de La Tribune de Genève durante el 22 de abril de 2012

IV. \#RadioLondres

V. ¿Fraude a la ley, tutela de la libertad de sufragio o maximización de la libertad de expresión en las redes sociales?

VI. La publicación de sondeos electorales en la legislación electoral federal en México

VII. La interacción ciudadana 2.0

* Instituto de Investigaciones Jurídicas de la UNAM.

D. R. ( ) 2012. Universidad Nacional Autónoma de México-Instituto de Investigaciones Jurídicas. 


\section{La primera vuelta de la elección presidencial francesa del 22 de abril de 2012}

A partir del análisis de lo acontecido durante la primera vuelta de la elección presidencial en Francia, es posible prever una serie de acciones emprendidas por la ciudadanía en el marco del espacio libertario que ofrece Internet, particularmente en las denominadas redes sociales. Hoy la ciudadanía participa interactivamente en las plataformas comunicativas 2.0, construyendo anhelos y materializando añejas aspiraciones sociales; una de ellas, mayor participación ciudadana. El tema de la ciberciudadanía como una aproximación conceptual, ahora se convierte en un ejercicio real y pragmático de participación política directa desde un contexto globalizado y esencialmente telemático.

Precisamente, durante la primera vuelta en la elección para presidente de la República en Francia, en forma reiterada diversos medios digitales suizos y belgas difundidos a través de la Internet, han publicado sondeos de opinión que han reflejado las tendencias del sufragio público del cuerpo electoral francés; a pesar de existir restricción legal sobre este asunto en particular. En estricto sentido, el problema no ha sido la difusión en Internet de los sondeos de opinión vinculados a las preferencias políticas de los franceses; el hecho cuestionable y en abierta violación a las disposiciones electorales aplicables a esta elección francesa, es que lo han realizado antes de la etapa de cierre de los centros de votación en Francia, situación que de facto podría incidir en una notoria influencia política a los electores franceses que aún no han sufragado, mismos que su opción política podría derivar en una actitud de sufragar bajo la concepción de un voto útil. El elemento central de este debate, se constriñe fundamentalmente al ejercicio ciudadano en un contexto de libertad al momento de emitir su sufragio público. Sin embargo, las nuevas tecnologías de la información y comunicación (TIC) y su principal herramienta, la Internet, han redimensionado por completo la libertad de sufragio cuando la vinculamos a ciertas conductas desplegadas a través del ciberespacio.

La publicación de sondeos o preferencias electorales en el marco de la legislación electoral francesa, se encuentra prevista en la Ley núm. 77-808 del 19 de julio de 1977 relativa a la publicación y a la difusión de ciertos sondeos de opinión, concretamente en el artículo 12 y subsecuentes. Adicionalmente, este cuerpo legal citado tiene una inter- 
pretación sistemática con el Código Electoral francés en su artículo L. 90-1, mismo que establece lo siguiente:

Article L. 90-1

Toute infraction aux dispositions de l'article L. 52-1 sera punie d'une amende de 75000 euros (énfasis añadido).

Por su parte, la restricción legal y punibilidad de publicar los sondeos de opinión que tienen relación con las tendencias electorales de forma previa a los cierres de los centros de votación, también encuentra su sustento legal en artículo L. 52-1 del propio Código Electoral francés, mismo que señala a la letra:

\section{Article L. 52-1}

Pendant les six mois précédant le premier jour du mois d'une élection et jusqu'à la date du tour de scrutin où celle-ci est acquise, l'utilisation à des fins de propagande électorale de tout procédé de publicité commerciale par la voie de la presse ou par tout moyen de communication audiovisuelle est interdite.

A compter du premier jour du sixième mois précédant le mois au cours duquel il doit être procédé à des élections générales, aucune campagne de promotion publicitaire des réalisations ou de la gestion d'une collectivité ne peut être organisée sur le territoire des collectivités intéressées par le scrutin. Sans préjudice des dispositions du présent chapitre, cette interdiction ne s'applique pas à la présentation, par un candidat ou pour son compte, dans le cadre de l'organisation de sa campagne, du bilan de la gestion des mandats qu'il détient ou qu'il a détenus. Les dépenses afférentes sont soumises aux dispositions relatives au financement et au plafonnement des dépenses électorales contenues au chapitre $\mathrm{V}$ bis du présent titre (énfasis añadido).

En este sentido, de igual forma la Commission Nationale de Contrôle de la Campagne Électorale en Vue de L'Élection Présidentielle, mediante un comunicado del 23 de abril de $2012,{ }^{1}$ ha reiterado de forma precisa la restricción de difundir por cualquier medio - esto incluye a la In-

1 Commission Nationale de Contrôle de la Campagne en Vue de l'Élection Présidentielle. Recommandation de report de l'horaire de fermeture des bureaux de vote pour le second tour de lélection présidentielle de 2012. Communiqué du 23 avril 2012. Consultado en: http://www.cnccep.fr/communiques-de-presse.html el 24 de abril a las 15:20 horas. 
ternet- algún tipo de sondeo o estimación de los resultados electorales antes del cierre de los centros de votación. Cabe precisar que esta prohibición como lo hemos señalado anteriormente, implica que no se puede poner en conocimiento de la opinión pública las tendencias electorales a través de los medios de comunicación.

No obstante, la propia Comisión reconoció que, en general, los grandes medios de comunicación respetaron la prohibición durante la jornada electoral del 22 de abril de 2012. Sin embargo, en las redes sociales, la difusión de los sondeos o tendencias de la elección presidencial francesa se generaron con bastante antelación a las 20:00 horas del día de la jornada comicial mediante un canal de comunicación establecido en la red social Twitter a través del hashtag (HT) \#RadioLondres. $\mathrm{Al}$ respecto, es pertinente destacar la difusión vía Internet de las tendencias electorales por conducto del diario suizo La Tribune de Genève, mismo que ha sostenido públicamente que su acción es legal y en el ejercicio de la libertad de expresión; su principal argumento jurídico y lógico desde luego es que precisamente "la legislación francesa no les resulta aplicable"; lo cual, en estricto sentido resulta cierto.

\section{El caso de La Tribune de Genève en 1997}

La Tribune de Genève constituyó en 1997 un caso paradigmático en el contexto electoral mundial, cuyo resultado ha sido la obsolescencia de las reglas electorales frente a la red mundial. Para algunos autores como Javier del Rey Morató, en Francia desde 1997, la Internet hizo su propio juego del oráculo en el plano electoral (Del Rey, 2007). Durante este episodio, los internautas franceses tuvieron acceso al sitio www.edicom.Ch/tgd, mismo que cuatro días antes de la jornada electoral difundió cuál era la intención de voto de los franceses. ${ }^{2}$ En este mismo sentido actuó la cadena de información CNN International, los diarios Libération y la République des Pyrénées por medio de Internet. Con posterioridad, durante la segunda vuelta electoral, dos días antes

2 Del Rey Morató, Javier, Comunicación política, Internet y campañas electorales de la teledemocracia a la ciberdemocr@cia, Madrid, Tecnos, 2008. 
de la jornada comicial (30 de mayo de 1997) Le Parisien y France-Soir desplegaron acciones similares. ${ }^{3}$

\section{La reincidencia de La Tribune de Genève durante el 22 de abril de 2012}

Es importante destacar que durante la primera vuelta de la elección presidencial francesa, nuevamente el diario suizo La Tribune de Genève incurrió en la difusión de las tendencias electorales en su sitio web $h t t p: / / w w w . t d g . c h$ (véase imagen 1), cuando menos una hora treinta minutos antes del cierre oficial de los centros de votación franceses. El tema central sobre la acción desplegada por este medio de comunicación es que precisamente a pesar de la restricción legal de orden electoral prevista en Francia, no obliga a los suizos; esto es, no hay competencia de la Comisión Nacional que regula la elección presidencial en el país galo y adicionalmente como hemos indicado en múltiples citas, la legislación no les resulta aplicable.

\section{Imagen 1}

La publicación de La Tribune de Genève el 22 de abril de 2012

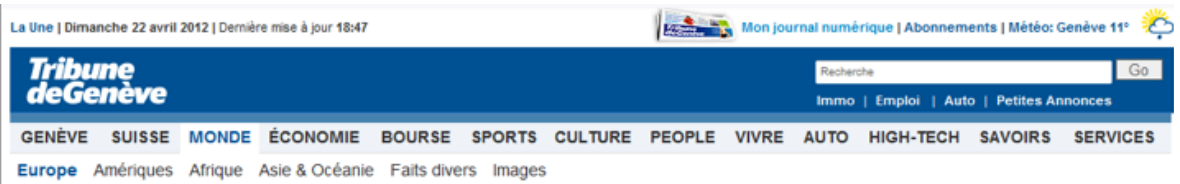

PRÉ SIDENTIELLE FRANÇAISE

François Hollande en tête, Marine Le Pen troisième

Par Marion Moussadek. Marc-Henri Jobin, Jugurtha Ait-Ahmed.

Grégoire Nappey et les agences. Mis à jour le 22.04.2012

Suivez la présidentielle en direct

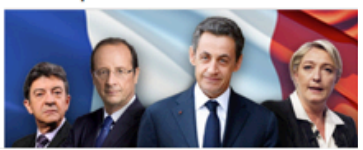

3 Idem. 


\section{IV. \#RadioLondres}

Como si tratare de un espacio natural para la ciudadanía, ahora sus procesos comunicativos gravitan esencialmente en las redes sociales. \#RadioLondres ahora constituye un paradigma en los procesos de comunicación política donde el ciudadano se convierte en un actor político proactivo en el marco de las redes sociales. Durante la jornada electoral del 22 de abril de 2012, la ciudadanía se organizó mediante este hashtag para difundir las tendencias electorales en Francia de una forma inédita y poco vista en la historia de las democracias contemporáneas (véase imagen 2). Aunado a lo que precede, se establecieron códigos comunicativos formulados espontáneamente por la ciudadanía para distinguir a los diversos candidatos y ligarlos a las tendencias de votación. Por ejemplo, el candidato socialista François Hollande tenía como claves en \#RadioLondres las siguientes: "Áms-terdam", "Gouda", "Flanby", “Tulipán", entre otras claves que sirvieron durante toda la jornada para distinguirle de otros candidatos y vincularlo a las preferencias del cuerpo electoral francés. No se omite señalar que si bien es cierto, estas conductas desplegadas por los cibernautas constituyen a priori una simulación de cumplimiento o respeto a la ley, o bien conforman un franco y abierto desafío a las instituciones jurídicas francesas. Cabe destacar que desde el 20 de abril de 2012, precisamente dentro de la etapa en que se encontraba vedado publicar algún tipo de sondeo o encuesta electoral surgió en redes sociales el hashtag \#JeRespeteLeCodeElectorale (véase imagen 3) cuyo interés primigenio era sortear la restricción legal de los artículos L. 90-1 y L. 52-1 del Código Electoral francés y comunicar principalmente lo que la mayoría de los electores franceses había expresado con toda libertad a través de sondeos previos. 


\section{Imagen 2 \\ HT \#RadioLondres}

Las elecciones francesas se debaten 'en clave' en \#Twitter: sondeos

filtrados en \#RadioLondres goo gl/FyMq9

Mélissa M.

4 Responder $\lfloor 7$ Retwittear $\$$ Favorito - Abrit

RT @edouardmabille: Au depart de la France :Amsterdam 28€,

Budapest 25€. Nuremberg 16€. Moscou 14€. Jupiter : $0.25 €$

\#RadioLondres

Ballet de Jaguar sur I'A10 direction la Suisse \#RadioLondres

\section{Imagen 3 \\ HT. \#JeRespeteLeCodeElectorale}

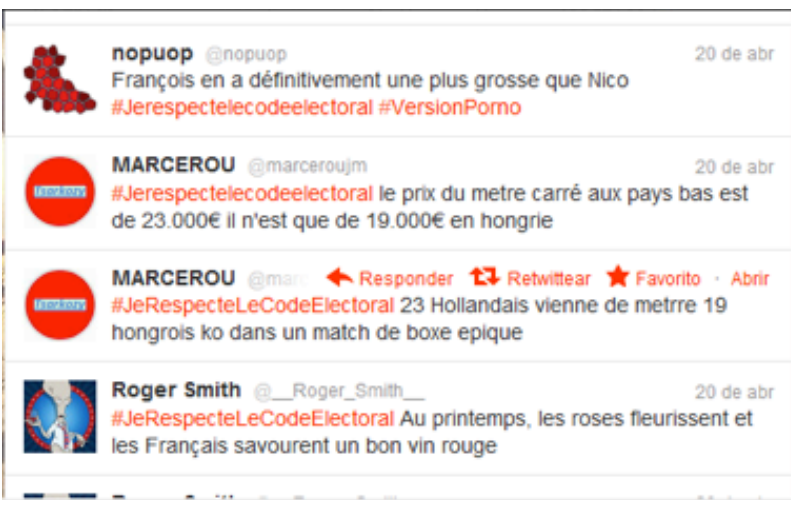




\section{V. ¿Fraude a la ley, tutela de la libertad de sufragio o maximización de la libertad de expresión en las redes sociales?}

Es importante reflexionar que la experiencia que nos arroja el caso francés puede dirigirnos a una permanente tensión entre la libertad del sufragio público y la libertad de expresión ahora en el contexto de las redes sociales. Lo anterior, reviste una importancia mayúscula desde la teoría jurídica, tenemos una tensión entre dos libertades fundamentales, en ambas debe prevalecer el interés colectivo. En este caso ¿cómo ponderamos?, ¿cuál principio fundamental retrotraemos para darle prevalencia a otro? En ambas, está latente el interés de la sociedad. La pregunta desde la ciencia del derecho ¿qué libertad debe tener prelación?, ¿es más importante la tutela del sufragio público? O bien, ¿es más importante la tutela de la libertad de expresión? En esta última reflexión, tendríamos que considerar qué tanto existe la afectación de un tercero - en este caso la sociedad o el ciudadano- en el ejercicio de esa libertad de expresión o si realmente existe una afectación para alguien, porque parece ser que nos constituimos en una especie de ombusdman colectivo que tutela el sacramental derecho de voto, y habría que preguntar quién se arroga esa facultad y preguntarle a la sociedad, si la difusión de una tendencia electoral en redes sociales realmente le afecta a la sociedad o al propio ciudadano.

Por otra parte, desde la teoría jurídica, habría que analizar si estas acciones desarrolladas por la propia ciudadanía y los medios de comunicación constituirían una especie de "fraude a la ley". Al respecto, desde la doctrina de los tratadistas Manuel Atienza y Juan Ruiz Manero, "el fraude de ley suele presentarse como un supuesto de infracción indirecta de la ley", a diferencia de los ilícitos llamados típicos, en los que se da un comportamiento que se opone directamente a ley. La estructura del fraude consistiría, en una conducta que aparentemente es conforme a una norma (a la llamada norma de cobertura), pero que produce un resultado contrario a otra u otras normas o al ordenamiento jurídico en su conjunto, misma que suele referirse como norma defraudada. ${ }^{4}$

\footnotetext{
4 Atienza, Manuel y Ruiz Manero, Juan, Ilícitos atípicos, Madrid, Trotta, 2000.
} 


\section{La publicación de sondeos electorales en la legislación electoral federal en México}

Nuestra legislación comicial en materia federal establece una restricción muy puntual para divulgar encuestas o sondeos de opinión que tengan por objetivo publicar las tendencias electorales. El principio electoral que subyace en esta disposición se orienta a la libertad de sufragio; esto es, la posibilidad de que el ciudadano durante un periodo de reflexión tome su decisión política sin ningún tipo de coacción, presión o influencia que podrían generar las tendencias o encuestas sobre las diversas preferencias políticas previas al día de la jornada electoral. Al respecto, el artículo 237, numeral 6, del Código Federal de Instituciones y Procedimientos Electorales dispone lo siguiente:

Artículo 237.-...

6. Durante los tres días previos a la elección y hasta la hora del cierre oficial de las casillas que se encuentren en las zonas de husos horarios más occidentales del territorio nacional, queda prohibido publicar o difundir por cualquier medio, los resultados de encuestas o sondeos de opinión que tengan por objeto dar a conocer las preferencias electorales de los ciudadanos, quedando sujetos quienes lo hicieren, a las penas aplicables a aquellos que incurran en alguno de los tipos previstos y sancionados en el artículo 403 del Código Penal Federal (énfasis añadido).

Cabe mencionar que este precepto electoral tiene una relación sistemática con el artículo 403 del Código Penal Federal, mismo que señala:

Artículo 403.- Se impondrán de diez a cien días multa y prisión de seis meses a tres años, a quien:

XIII. Durante los ocho días previos a la elección y hasta la hora oficial del cierre de las casillas que se encuentren en las zonas de husos horarios más occidentales del territorio nacional, publique o difunda por cualquier medio los resultados de encuestas o sondeos de opinión que den a conocer las preferencias de los ciudadanos. 
En un comparativo entre la legislación electoral francesa y la mexicana, la misma conducta como acto electoral puede tener efectos jurídicos de naturaleza penal. Por una parte, en Francia se constituye como una conducta con efectos punitivos cuya sanción se puede constituir en una multa equivalente de hasta 75000 euros. Por otra parte, la legislación comicial federal en México establece que la misma conducta desplegada tiene también efectos de naturaleza penal, constituyéndose así como una conducta punible que con independencia de la multa, sus efectos se extienden a una esfera de la restricción de la libertad del inculpado, misma que podría ser de seis meses a tres años de prisión.

\section{La interacción ciudadana 2.0}

Las redes sociales en el contexto de la comunicación política se han convertido en una especie de "ágora en su versión electrónica”. Ahora, se han constituido como el punto de partida de acciones colectivas eficaces para inclusive modificar sistemas políticos. ${ }^{5}$

Hoy el ciudadano, siente una gran comodidad y libertad para participar en asuntos de interés general en el contexto de las redes sociales y empiezan a privilegiar esta vía telemática. Hoy existe adicionalmente, una tendencia por fomentar, consolidar y dar continuidad a la participación ciudadana; más aún, comenzamos a colocar en el centro del debate la llamada "ciudadanía digital". En su oportunidad, el constitucionalista español Antonio Enrique Pérez-Luño, le ha denominado "ciberciudadanía".

En este contexto de búsqueda respecto de una mayor participación ciudadana a través de entornos digitales dentro de la sociedad de la información y la creciente importancia social, jurídica y política de estas nuevas plataformas comunicativas 2.0; los efectos de las redes sociales dentro de los sistemas y órdenes jurídicos resultan completamente asimétricos al mundo del derecho. Las disposiciones electorales operan de forma muy diferente en el ámbito del ciberespacio,

5 Basta analizar el caso de la "primavera árabe" y la función que cumplieron las redes sociales para la organización ciudadana. 
particularmente en el contexto de las redes sociales o simplemente no tienen vigencia.

En síntesis, podemos señalar que las disposiciones electorales operan de forma asimétrica respecto de lo que sucede en el contexto de las redes sociales. Las normas electorales no serán un dique para la comunicación personal en el ciberespacio o para divulgar tendencias electorales, los ciudadanos en Internet operan de manera diferente sin tener en cuenta o cumplir necesariamente el marco jurídico electoral, valdría la pena reflexionar si podemos contener estas acciones ciudadanas crecientes desde el derecho electoral. Más aún, ¿deberíamos? La respuesta la tendrá la ciudadanía el próximo primero de julio. Parece que hoy, las legislaciones electorales y la capacidad de las autoridades electorales para contener conductas en el ciberespacio, se han vuelto insuficientes u obsoletas ante el mundo de las redes sociales. Finalmente, las propias redes sociales pueden representar el inicio de un proceso de empoderamiento ciudadano. 